\title{
Spatiotemporal Analysis of Evapotranspiration and Effects of Water and Heat on Water Use Efficiency
}

\author{
Yuan-Yuan Tang ${ }^{1,2}$, Jian-Ping Chen ${ }^{1, *}$, Feng Zhang ${ }^{3}$ and Shi-Song Yuan ${ }^{3}$ \\ 1 School of Earth Science and Resouces, China University of Geosciences (Beijing), Beijing 100083, China; \\ 3001160121@cugb.edu.cn \\ 2 Changsha Natural Resources Comprehensive Survey Center, China Geological Survey, \\ Changsha 410000, China \\ 3 Geophysical Survey Center, China Geological Survey, Langfang 065000, China; \\ zhangfeng01@mail.cgs.gov.cn (F.Z.); yuanshisong@mail.cgs.gov.cn (S.-S.Y.) \\ * Correspondence: 3s@cugb.edu.cn
}

Citation: Tang, Y.-Y.; Chen, J.-P.; Zhang, F.; Yuan, S.-S. Spatiotemporal Analysis of Evapotranspiration and Effects of Water and Heat on Water Use Efficiency. Water 2021, 13, 3019. https://doi.org/10.3390/w13213019

Academic Editors: Mirko Castellini, Simone Di Prima, Ryan Stewart, Marcella Biddoccu, Mehdi Rahmati and Vincenzo Alagna

Received: 15 August 2021

Accepted: 21 October 2021

Published: 27 October 2021

Publisher's Note: MDPI stays neutral with regard to jurisdictional claims in published maps and institutional affiliations.

Copyright: (c) 2021 by the authors. Licensee MDPI, Basel, Switzerland. This article is an open access article distributed under the terms and conditions of the Creative Commons Attribution (CC BY) license (https:/ / creativecommons.org/licenses/by/ $4.0 /)$.

\begin{abstract}
Water Use Efficiency (WUE) is an important indicator of the carbon cycle in the hydrological and ecological system. It is of great significance to study the response of different hydrological processes to climate and to understand ecosystem carbon sink. However, little is known about the effects and mechanisms of precipitation and temperature on the WUE of different hydrological processes. Thus, three kinds of WUEs (GPP/E (eWUE), GPP/Et (tWUE), and GPP/P (pWUE)) are defined for three different hydrological indicators in semi-arid areas in this study in order to reveal the variation pattern of WUEs based on hydrological indicators and their response to climate. We found that in the past 15 years, the seasonal fluctuation of evapotranspiration in arid areas was large, and the spatial difference of WUE of different hydrological processes was obvious. In semi-arid areas, temperature had a significant effect on WUE (about 68-81\%). However, precipitation had a lag effect on WUEs, and the negative impact of precipitation has a great influence (about $84-100 \%$ ). Secondly, the threshold values of precipitation to WUEs (200 or $300 \mathrm{~mm}$ ) and temperature to WUEs $\left(2\right.$ or $\left.7^{\circ} \mathrm{C}\right)$ are also different from previous studies. This study advances our understanding of the influence of different hydrological processes on ecosystem carbon and climate.
\end{abstract}

Keywords: evapotranspiration; spatial and temporal; water use efficiency; Gleam Product

\section{Introduction}

Terrestrial ecosystems are a major carbon sink in the global carbon cycle [1]. The issue of how the carbon and water cycles can be balanced is of great interest to the scientific community [2]. WUE is an important indicator of the coupling of carbon and water cycles in ecosystems, which closely links biological processes (photosynthesis, transpiration) and physical processes (evaporation). It is a key parameter for ecosystem response to climate change [3].

WUE controls the coupling between plant water use and carbon assimilation and has been defined in many previous studies as the ratio of GPP (gross primary productivity) to evapotranspiration [4,5]. In some GPP simulation models, WUE is also a critical metric [6]. Recently, other studies have determined the effects of changes in vegetation, climate, land use, and atmospheric $\mathrm{CO}_{2}$ on changes in WUE [7-9]. Responses of ecosystem WUE's to climate are generally primarily based on spatial or temporal gradient analysis [10]. Due to the uncertain interactions of many environmental factors on WUE, it is still yet to be tackled how to accurately predict the regional impact of climate change on carbon water resources [11]. The application of the mechanism model makes it possible for WUE to expand from the blade or regional to the global level, so as to explore the impact of single and multiple environmental factors on WUE greatly. Climate factors such as precipitation and 
temperature can sensitively reflect climate change in arid and semi-arid areas [11]. Evaporation, transpiration, and precipitation, which regulate the growth of plants, are important parts of the water cycle. Huang et al. (2016) defined the GPP/p and GPP/Et (transpiration) ratio as a new indicator of water efficiency and have been widely applied [12]. Yang et al. discussed the ecosystem response mechanism to drought by comparing the responses of different terrestrial ecosystems around the global to drought [13].

WUE not only exhibits strong spatial heterogeneity but also has significant interannual changes. Spatially, areas with low WUE values are mainly located in Central Asia, the Sahel in Africa, the western coasts of North and South America, and areas such as Oceania, where evaporation is strong and vegetation is scarce [14]. Global WUEs have generally increased over the 30 years from 1982 to 2008, but they vary significantly from region to region, depending on the direction and magnitude of changes between the GPP and ET [14]. Among them, meteorological factors such as precipitation, temperature, and solar radiation were crucial factors driving WUE change [12]. However, due to the different geographical environments effect, the results obtained from different studies often vary significantly [15]. For example, in the water-scarce Black River basin, precipitation plays a leading role in WUE [16]. However, in the more humid alpine meadows, temperature is a more important factor [17]. There are very few studies of WUE in arid areas, especially based on newly defined indicators of water efficiency, and studies of climate responses have not been reported.

Xinjiang belongs to an arid and semi-arid area with a shortage of water resources and scarce surface vegetation. It has extremely fragile ecosystems, and the impact of climate change is severe [18-20]. The process of small water circulation in inland Xinjiang is accelerating, and the rapid melting of alpine ice and snow directly changes the composition of runoff recharge, affecting the water consumption of vegetation in mountains, oases, and deserts, and the growth of vegetation and spatial distribution patterns [21]. The total amount of water resources consumed in arid areas of Xinjiang is relatively large, leading to an increasing depletion of water resources. It has become the core restriction on the development and regional stability of Xinjiang [22]. Therefore, based on previous research, this study analyzed the multi-year spatial-temporal changes of Xinjiang evapotranspiration and WUE, and it quantitatively evaluated WUE's sensitivity to temperature and precipitation, providing data support for ecological restoration and water resource utilization and management in the region.

In summary, the objectives of this study are as follows: (1) monthly and annual scale changes and spatial changes of Xinjiang actual evapotranspiration and potential evapotranspiration ( $E p)$ were analyzed; then, $E$ and $E p$ trend changes can be predicted according to the Hurst index; (2) The spatiotemporal variation trend of based on different hydrological indicators of water use efficiency; (3) The response and threshold of different hydrological processes of WUE indexes to climate change were analyzed.

\section{Materials and Methods}

\subsection{Study Area}

Xinjiang is located in the hinterland of Eurasia and the northwestern border of China, with a geographical position of $34^{\circ} 15^{\prime} \mathrm{N}$ to $48^{\circ} 10^{\prime} \mathrm{N}, 73^{\circ} 20^{\prime} \mathrm{E}$ to $96^{\circ} 25^{\prime} \mathrm{E}$ (Figure 1). It has the unique landscape featuring three mountains. The aera is rich in glaciers, which is $46.9 \%$ of China's total glacial reserves. Rivers are mainly supplied with ice and snow melting water, the annual runoff is $8.79 \times 10^{10} \mathrm{~m}^{3}$, and the lake area exceeds $1.29 \times 104 \mathrm{~km}^{2}$ [23] As a result of its particular geographical location, topography, climate and other factors, the coverage rate of vegetation in the territory is low. Desert, gobi, and bare land are widely distributed, and the ecosystem is fragile [24]. 


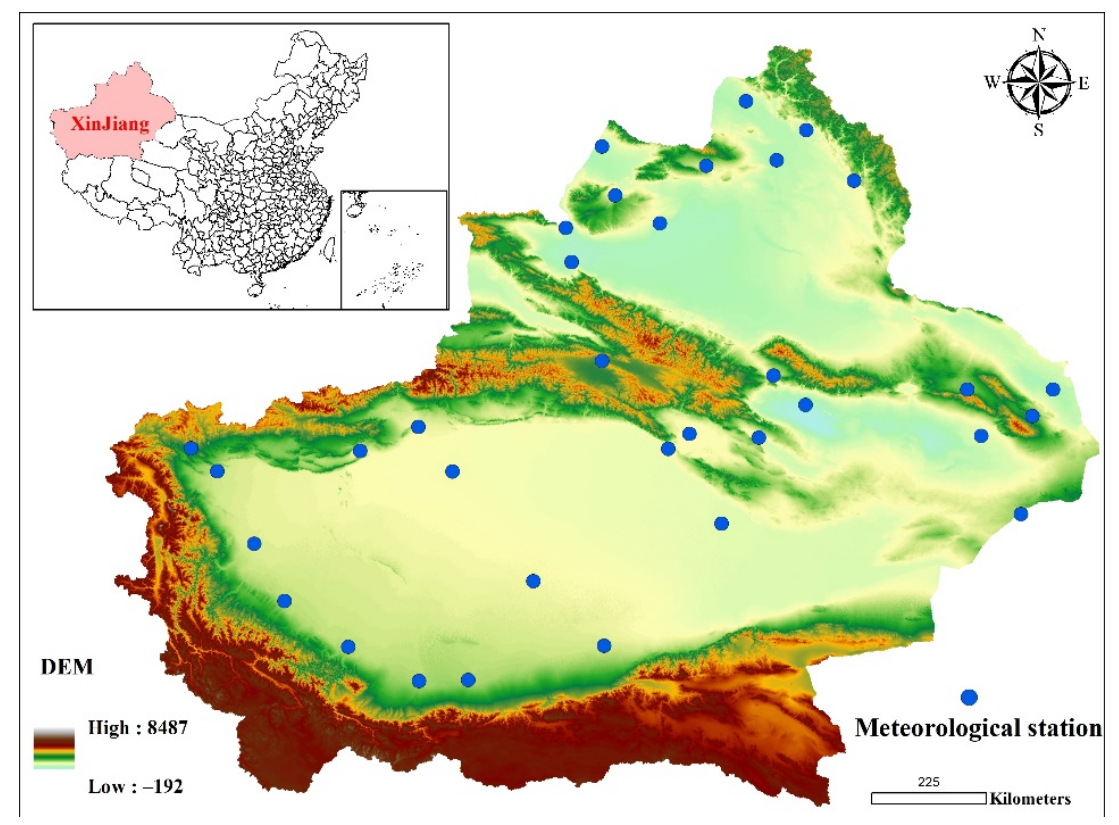

Figure 1. Location of the study area (the small picture inserted shows the geographical location of Xin-jiang).

\subsection{Evapotranspiration and Drought Index Data}

Gleam v3.3a (Global Land Evapotranspiration Amsterdam Model 3.3a) is a set of data estimating the different components of land surface evapotranspiration independently: actual evaporation $(E)$, potential evapotranspiration $(E p)$, transpiration $(E t)$, evaporation stress factor, root zone soil moisture, surface soil moisture, etc. [25]. This data product is based on the surface radiation and near-surface temperature of multiple reanalysis datasets, and the Gleam Ep dataset with a spatial resolution of $0.25^{\circ} \times 0.25^{\circ}$ is obtained by using the Priestley-Taylor formula. Evapotranspiration data are a monthly dataset (https: / /www.gleam.eu/) (accessed on 14 October 2021). GLEAM evapotranspiration products have been widely used in the field of hydrology and meteorology since their development [26]. These data has been applied by scholars to the study of the arid region of northwest China, and the data quality has been verified accordingly $[27,28]$. Therefore, monthly data of GLEAM V3.3A, E, Ep, and Et from 2000 to 2014 are used for data analysis.

Two drought indices, SPEI and PDSI, were selected in this paper. The SPEI dataset is provided by the National Cryosphere Desert Data Center. (http://www.ncdc.ac.cn) (accessed on 14 October 2021). The spatial resolution is $1^{\circ}$, and the temporal resolution is the monthly average from 2000 to 2014. The PDSI is the first comprehensive drought index developed and is most commonly used to assess the impact of drought on Agriculture in the United States. It was obtained from KNMI Climate Explorer (http:/ / climexp.knmi.nl/) (accessed on 14 October 2021), has a spatial resolution $1^{\circ}$, and the temporal resolution is the monthly average from 2000 to 2014 .

\section{Data Availability}

To verify the accuracy of GLEAM- $E$ in Xinjiang region, the daily datasets from 34 sites of the China Meteorological Data Network (http:// data.cma.cn/) (accessed on 14 October 2021) are used. Site scale assessment of surface evapotranspiration products was carried out. Due to the absence of observation data in time series, 132 valid observations were screened. The evaporating dish is the maximum evaporation condition of free water in the region under the condition of sufficient moisture [29]. In arid and semi-arid areas, the actual evapotranspiration is mainly determined by water and energy. At the same time, the evaporating dish evapotranspiration is not affected by moisture, and the main factor determining its size is solar energy. Therefore, the evaporating dish evapo- 
transpiration has an inverse relationship with the actual evapotranspiration, and potential evapotranspiration represents the maximum evapotranspiration of an underlying solid surface under sufficient water supply [30]. It can be seen that the evapotranspiration in the evaporating dish is close to the potential evapotranspiration in the GLEAM product, and the feasibility of the GLEAM-E product in the Xinjiang region can be verified by the correlation between the evapotranspiration and GLEAM-Ep. The results (Figure 2) show that there was a high correlation between the observations evapotranspiration and GLEAM-E $p$. The correlation coefficient $R^{2}=0.8654$, indicating that the GLEAM- $E$ product had good verification accuracy in the Xinjiang region, and the verification results meet the requirements.

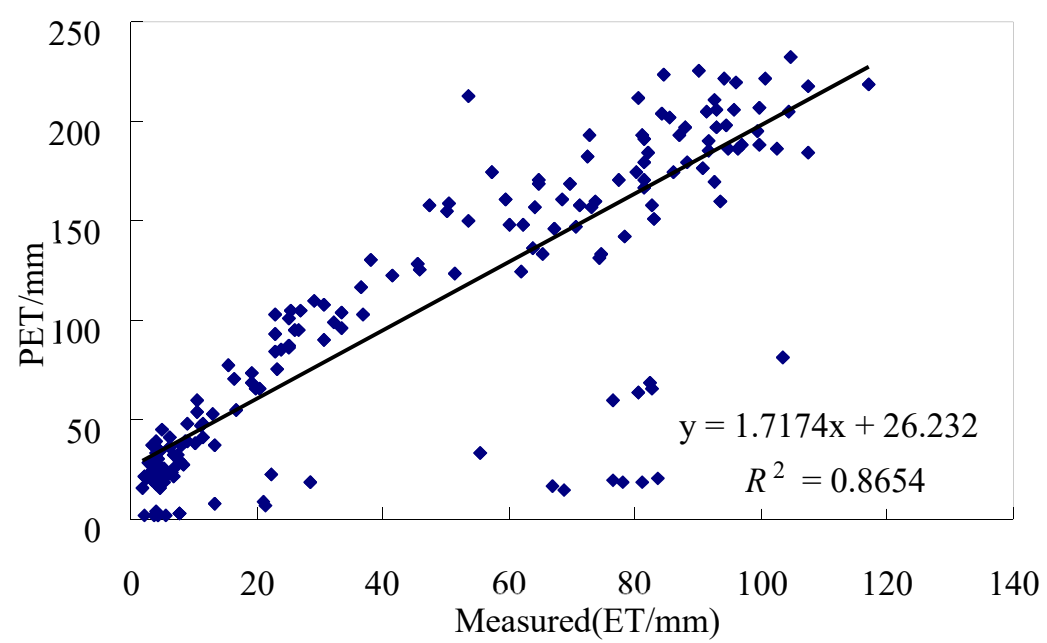

Figure 2. Relationship between GLEAM Ep product and observations evapotranspiration (measured represents observations of evapotranspiration; PET represents GLEAM Ep at meteorological stations.

\subsection{Precipitation and Temperature Data}

The monthly precipitation and temperature ( $2 \mathrm{~m}$ air temperature) data from 2000 to 2014 used in this study come from a dataset with a spatial resolution of $1 \mathrm{~km} \times 1 \mathrm{~km}$ [31]. The dataset shows the data of January 1901 to December 2017 in a time series from the National Tibetan Plateau Data Center (NTPDC) (http://data.tpdc.ac.cn) (accessed on 14 October 2021). The accuracy of this dataset has been verified and tested for good efforts [32,33]. Precipitation and temperature data spatial resolution was resampled to be $0.25^{\circ} \times 0.25^{\circ}$. The precipitation data were used to calculate WUE and temperature to analyze the response of WUE to climate.

\subsection{Gross Primary Production (GPP) Data}

The MOD17 product is the first continuous satellite-driven dataset that monitors global surface vegetation productivity and provides 8-day composite GPP products, net photosynthesis production products, and annual total GPP and NPP numerical products [34]. In MODIS satellite products, the standard product mod17a2h GPP of version 6 is a cumulative 8-day composite product with a spatial resolution of $1 \mathrm{~km}$. The GPP of this product was estimated according to the BIOME-BGC model of radiation utilization efficiency [35]. In addition, the algorithm of this product was based on the relationship between the total photosynthesis and the amount of photosynthetically active radiation absorbed by the plant canopy. For detailed calculation, please refer to Heinsch's literature [36]. In this study, GPP data from 2000 to 2014 were selected, and the spatial resolution was resampled to $0.25^{\circ} \times 0.25^{\circ}$. The GPP product was applied to calculate WUE.

\subsection{Land-Use/Land-Cover (LULC) Datasets}

The LULC dataset is collected from the resource and environmental data cloud platform released by the Chinese Academy of Sciences (http:/ / www.resdc.cn/Data/) (accessed 
on 14 October 2021). Then, we downloaded the LULC datasets in 2000 and 2015 and used ArcGIS 10.1 to extract the study area by mask. There are 25 types of raster datasets with a spatial resolution of $1 \mathrm{~km}$. According to the actual situation in Xinjiang, LULC types are reclassified into 6 types, including cultivated land, forest, grassland, construction and residential land, water, and unused land.

\subsection{Coefficient of Variation}

The coefficient of variation (CV) measures the degree of dispersion of random variables. It is used to analyze the spatial pattern and spatial differentiation of ET [37].We calculated the coefficient of variation of evapotranspiration and potential evapotranspiration from 2000 to 2014 by pixels and analyzed the stability of evapotranspiration and potential evapotranspiration in time series. The higher the $\mathrm{CV}$, the more discrete the data distribution is across years, which means the time series fluctuates and is unstable. Conversely, it indicates that the data distribution is relatively concentrated, and the time series is relatively stable.

\subsection{Hurst Index}

The Hurst index is used to describe the sustainability of time-series data quantitatively and has extensive applications in hydrology, economics, and climatology [38]. Consider the ET (ET represents variables) time series $E T(t)(t=1,2,3,4, \ldots, n)$, and define the mean sequence of the time series:

$$
\overline{E T}_{(\tau)}=\frac{1}{\tau} \sum_{t=1}^{\tau} E T_{(\tau)} \quad \tau=1,2, \ldots, n
$$

Calculate the cumulative dispersion as:

$$
X_{(t, \tau)}=\sum_{t=1}^{t}\left(E T_{(t)}-\overline{E T}_{(\tau)}\right) \quad 1 \leq t \leq \tau
$$

The sequence of the range:

$$
R_{(\tau)}=\underset{1 \leq t \leq \tau}{\max X_{(t, \tau)}}-\underset{1 \leq t \leq \tau}{\min X_{(t, \tau)}} \quad \tau=1,2, \ldots, n
$$

The standard deviation sequence is:

$$
S_{(\tau)}=\left[\frac{1}{\tau} \sum_{t=1}^{\tau}\left(E T_{(t)}-E T_{(\tau)}\right)^{2}\right]^{\frac{1}{2}} \quad \tau=1,2, \ldots, n
$$

Calculate the Hurst index:

$$
\frac{R_{(\tau)}}{S_{(\tau)}}=(c \tau)^{H}
$$

where $c$ is a constant. The Hurst empirical formula is obtained by using the logarithm of both sides of the method (5). Based on the time series and using Hurst's index, we get a cluster of $H$ values for least-squares fitted line, the slope of which is the modified Hurst index $(H)$, revealing the fractal characteristics of the time series.

\subsection{Calculation of WUEs}

WUE is defined as the ratio of the total primary productivity of terrestrial ecosystems to the actual vapor emplacement of ET in a unit of time [39]:

$$
\mathrm{WUEs}=\frac{\mathrm{GPP}}{H}
$$


where WUEs $\left(\mathrm{g} \mathrm{C} \cdot \mathrm{mm}^{-1} \cdot \mathrm{m}^{-2}\right)$ represents the water use efficiency, ET is the evapotranspiration, and GPP is the gross primary productivity. Here, we define three similar water use efficiencies; eWUE represents the ecosystem water use efficiency ( $H$ stands for evapotranspiration); tWUE is the vegetation transpiration water use efficiency ( $H$ stands for transpiration); and pWUE is the precipitation of water use efficiency ( $H$ stands for precipitation). Here, GPP and precipitation data with a spatial resolution of $1 \mathrm{~km}$ and a time scale of month are resampled with a spatial resolution of $0.25^{\circ} \times 0.25^{\circ}$. Finally, monthly WUEs are calculated.

This study used a linear trend estimation method to analyze the spatiotemporal change trend of WUEs. The $x$ axis is the year (time series), and the $y$ axis is the slope $y=a+b x$ of the WUEs, the linear regression equation representing the trend rate. When the slope is greater than zero, the WUEs are growing, and vice versa $[40,41]$. We have divide the trend change into five levels, as shown in Table 1.

Table 1. Scale of trend change.

\begin{tabular}{ccc}
\hline Slope $_{W U E}$ & Increase Degree & Abbreviations \\
\hline$\geq 0.40$ & High Increase & HI \\
$0.2 \leq$ Slope $_{W U E}<0.4$ & Relatively High Increase & RHI \\
$0.1 \leq$ Slope $_{W U E}<0.2$ & Medium Increase & MI \\
$0 \leq$ Slope $_{W U E}<0.1$ & Relatively Low Increase & RI \\
$-0.1 \leq$ Slope $_{W U E}<0$ & Low Decrease & LD \\
\hline
\end{tabular}

\subsection{WUEs Response to Climate Change}

We used the relative sensitivity of WUE to temperature and precipitation to estimate the impact of terrestrial ecosystem processes on climate response [13]. Firstly, we used the dplR package tool to detrend all variables. Second, we define sensitivity analysis with WUE as the dependent variable and temperature and precipitation as the independent variables. Finally, the estimated regression coefficient represents the sensitivity of each independent variable to the dependent variable [42]. The sensitivity coefficient calculation equation is as follows:

$$
S_{p}=\frac{\partial \mathrm{WUE}}{\partial P}
$$

where $S_{p}$ is the sensitivity coefficient; WUE is water use efficiency; and $P$ is air temperature or precipitation, respectively.

The correlation technique was used to calculate the coefficients (R) of each relationship between variables in the study, and the $p$ test was used to test $\mathrm{R}$ significance. The Rstudio Tool (https:/ / rstudio.com/) (accessed on 14 October 2021) and ArcGIS 10.2 Python (ArcGIS 10.2 and Python, ESRI, Redlands, CA, USA) were employed to calculate and model using all datasets.

\section{Results and Discussion}

\subsection{Temporal Variation in $E$ and $E p$}

Considering the fact that $E$ represents the actual evapotranspiration and $E p$ represents the potential evapotranspiration under sufficient water supply conditions, the difference between $E p$ and $E$ can reflect the drought situation in the study area [43,44]. From Figure 3a, it is shown that the difference between $E p$ and $E$ in Xinjiang is relatively large in 2000-2014. Among these years, the difference between $E p$ and $E$ was the largest in 2008, reaching around $1200 \mathrm{~mm}$. The difference in 2003 was the wettest and is about $1000 \mathrm{~mm}$. Hence, the drought degree was the biggest in 2008 and the wettest in 2003. We can also see from Figure 3c,d that the year 2008 was the driest and 2003 was the wettest. It can be seen from Figure $3 c, d$ that the drought situation in Xinjiang gradually alleviated, which is consistent with the findings of previous studies that precipitation is increasing in Xinjiang. Figure $3 \mathrm{~b}$ shows the monthly trend of $E$ and $E p$. Specifically, the difference between $E$ and $E p$ is the largest in July and the smallest in January, and the differences are around 
$170 \mathrm{~mm}$ and $15 \mathrm{~mm}$ respectively. This indicates that the drought degree is the largest in July and the smallest in January. Overall, in spring (March-May), both $E$ and $E p$ were in an increasing state. As the temperature rises as well as the melting of snow and ice increases, the transpiration of vegetation increases and evaporation increases. In summer (June-August), $E$ and $E p$ reached the peak, and the temperature is the highest at this time. Under the influence of westerly wind, water vapors, rainfall, and vegetation are abundant. In autumn (September-November), the temperature drops, vegetation withers, and transpiration weakens, leading to the gradual decrease in $E$ and $E p$. The temperature in winter (December-February) reached the lowest, with less precipitation and radiation, and $E$ and $E p$ reduced to the lowest. From 2000 to 2014, the $E$ and $E p$ seasonal changes are significant.
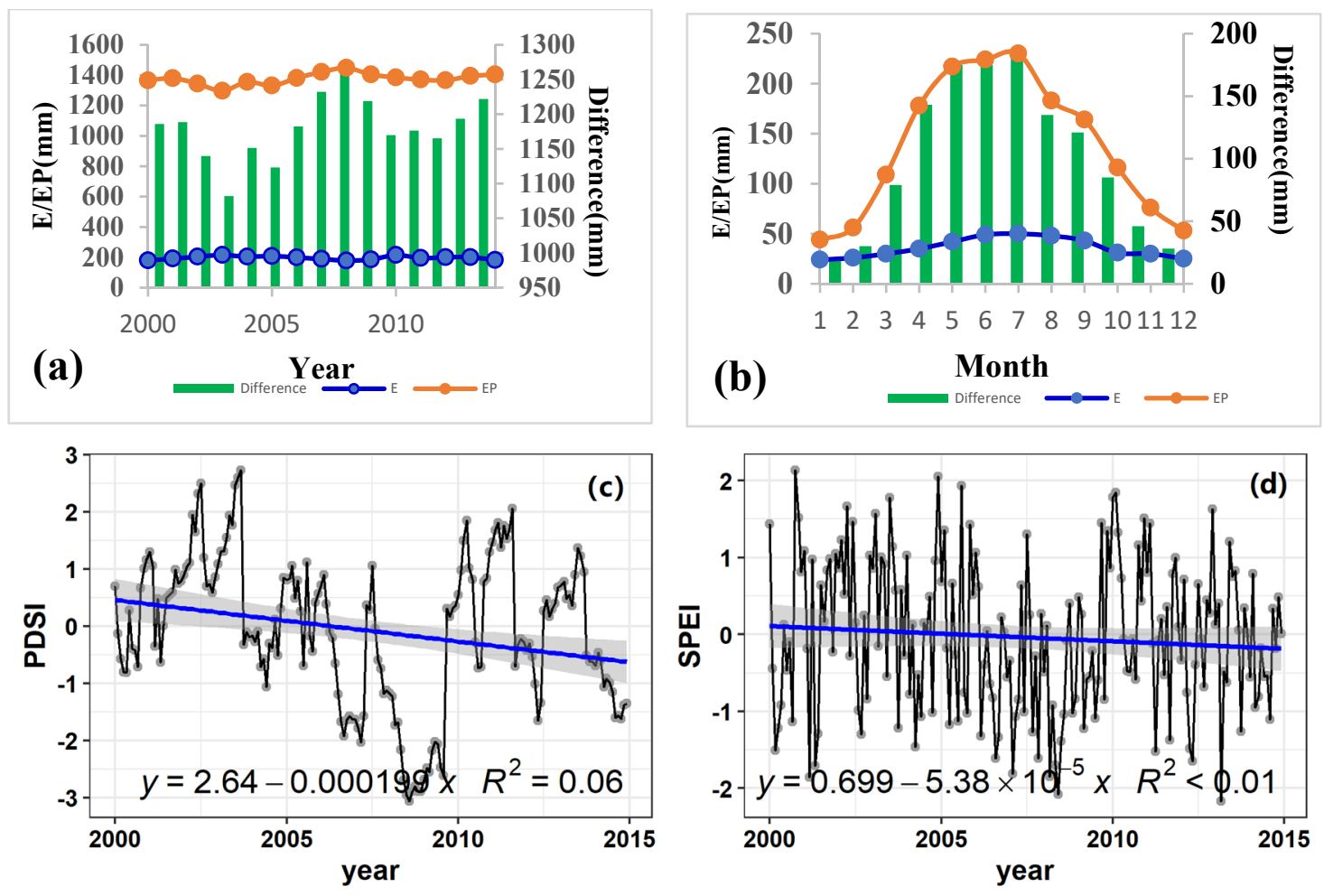

Figure 3. Annual and monthly variations of $E$ and $E p$ in Xinjiang during 2000-2014. (a) Annual mean changes; (b) Monthly mean changes; (c) Trends of PDSI monthly scale variation; (d) Trends of SPEI monthly scale variation).

\subsection{Stability Analysis of Evapotranspiration}

In order to further understand the spatial stability pattern of $E$ and $E p$ in Xinjiang, we used the coefficient of variation method for analysis. The CV of $E$ and $E p$ is divided into five levels, with CV less than 0.05 defined as low fluctuation, 0.05 to 0.10 defined as low to moderate fluctuation, 0.10 to 0.15 defined as moderate fluctuation, 0.15 to 0.20 defined as moderate to strong fluctuation, and greater than 0.20 defined as very strong fluctuation.

According to Figure 4a, the CV value of $E$ near Yili River Valley, Tacheng, and Kunlun Mountain is significantly larger than 0.2 , which indicates that the interannual $E$ in this region has large fluctuations. 

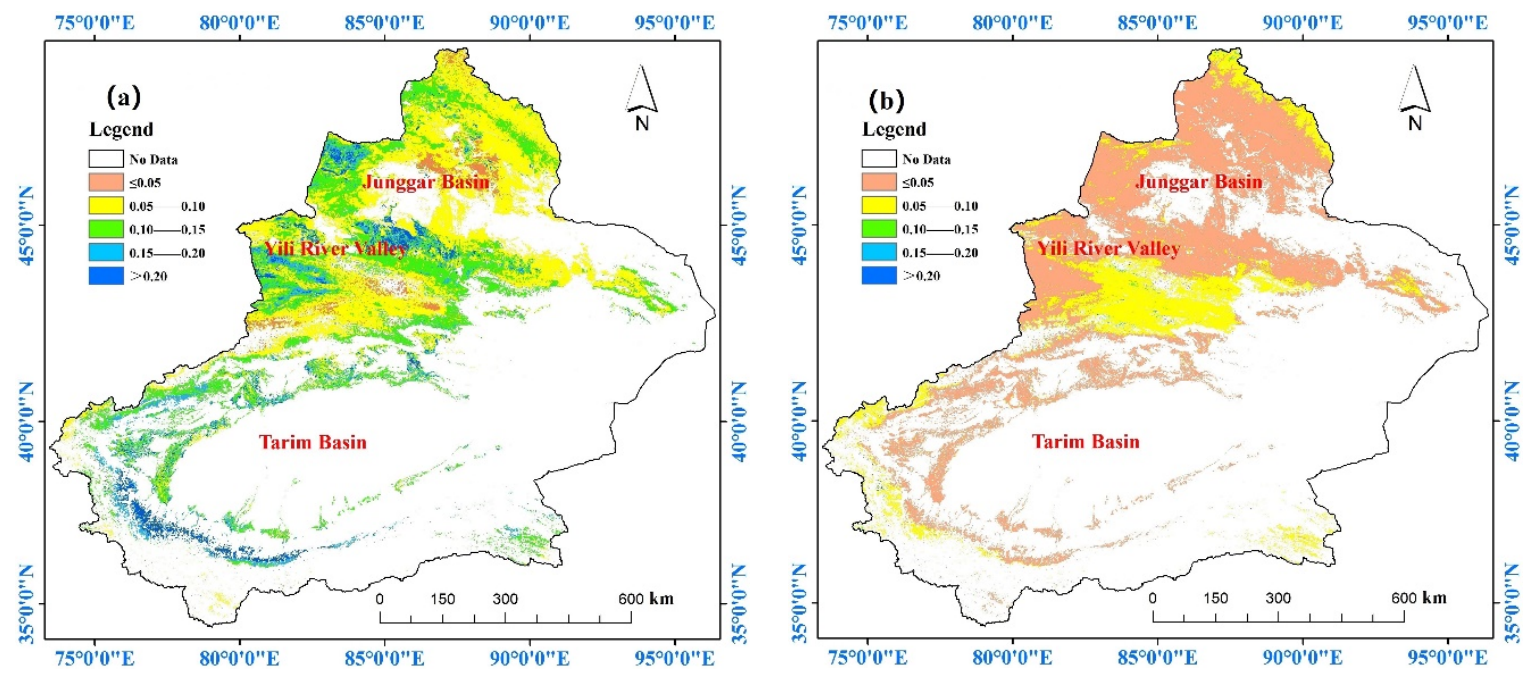

Figure 4. Spatial distribution of variation coefficient of E and Ep in Xinjiang. (a) E; (b) Ep.

The $E$ is the most unstable, while the $\mathrm{CV}$ of the Junggar Basin and the vicinity of the Tianshan Mountains is the lowest (less than 0.1), indicating that the interannual $E$ fluctuation in this region is small. The time-series fluctuation is the most stable and the time-series fluctuation of $E$ in northern Xinjiang (to the north of the Tianshan Mountains) is more durable than that in southern Xinjiang. This may be due to the continuous "warm and wet" conditions in the northwest [45]. From Figure 4b, we can see that the CV values of $E p$ in Xinjiang are all low (less than 0.1$)$, and the minimum $C V$ values $(\leq 0.05)$ are mainly distributed in the vicinity of the Junggar Basin. The larger CV $(0.05-0.1)$ is primarily distributed near the Tianshan Mountains; it shows that the Ep's space sequence in Xinjiang is relatively stable, and the stability of the Junggar Basin is most significant. To sum up, the regions with large fluctuations in evapotranspiration in Xinjiang are mainly located around the Yili River Valley and the Tarim Basin. The possible reason is that the vegetation in these areas has poor water conservation capacity, causing the interannual evapotranspiration to vary greatly.

LULC also affected the spatial pattern of $E$ and $E p$. As can be seen from Figure A1, the regions with strong fluctuations of $E$ are mainly distributed in cultivated land, grassland and forest land in mountainous areas such as Tianshan mountains, Altai mountains, Qilian mountains and Yili river valley. The regions with low ET fluctuation are mainly in the margin of Tarim Basin in southern Xinjiang and Junggar Basin in northern Xinjiang. Meanwhile, the ET of agricultural land in oasis is higher than that of unused land at oasis edge. According to the changes of different land cover types (Figure A1C), cultivated land increased by $1.08 \%$, grassland decreased by $0.66 \%$, and woodland decreased by $0.08 \%$. From the perspective of spatial differences, the difference in dynamic and thermal properties of different land covers leads to the redistribution of energy in the land-air interaction [46]. Secondly, due to artificial planting and irrigation, vegetation coverage and soil moisture in cultivated areas are higher than those in other areas, which makes evapotranspiration show significant spatial heterogeneity.

\subsection{Hurst Index}

The Hurst index method is used to analyze the sustainability of the time series of $E$ and $E p$ in Xinjiang from 2000 to 2014 (Figure 5a). It can be seen that the regions with an $E$ Hurst index less than 0.5 are mainly distributed in the northern Junggar Basin region, which shows that the future $E$ variations in this region are contrary to the past. As northern Xinjiang is mainly an area with more agricultural land and greater land use change, the future trend of evapotranspiration in this region is opposite to that in the past. Most of the rest of the areas have a Hurst index of more than 0.5, indicating that the regional distribution of $E$ in the vast majority of regions in Xinjiang is consistent with the trend 
of the past. The change of $E$ Hurst index from 2000 to 2014 shows continuity. The most persistence is near the Tianshan Mountains, and the $E$ Hurst index in this region is mostly above 0.8 from 2000 to 2014 .

The region with an $E p$ Hurst index less than or equal to 0.5 is mainly distributed in the Yili River valley in northern Xinjiang, indicating that the future $E p$ changes in this area are contrary to the past. The areas with a Hurst index greater than 0.5 for Ep are mainly distributed in the Junggar Basin, the nearby Tianshan Mountains, and near Tarim River Basin in northern Xinjiang. The Hurst index indicates that the Ep in these regions is consistent with past trends, and the entire process is continuous. The Tianshan Mountains and the Junggar Basin have the most robust persistence, and the Hurst index in the eastern part of the Tianshan Mountains is above 0.9. In conclusion, $E$ and $E p$ in Xinjiang will continue for a period of time in line with the past trend with no turning point, and the volatility is relatively unstable.
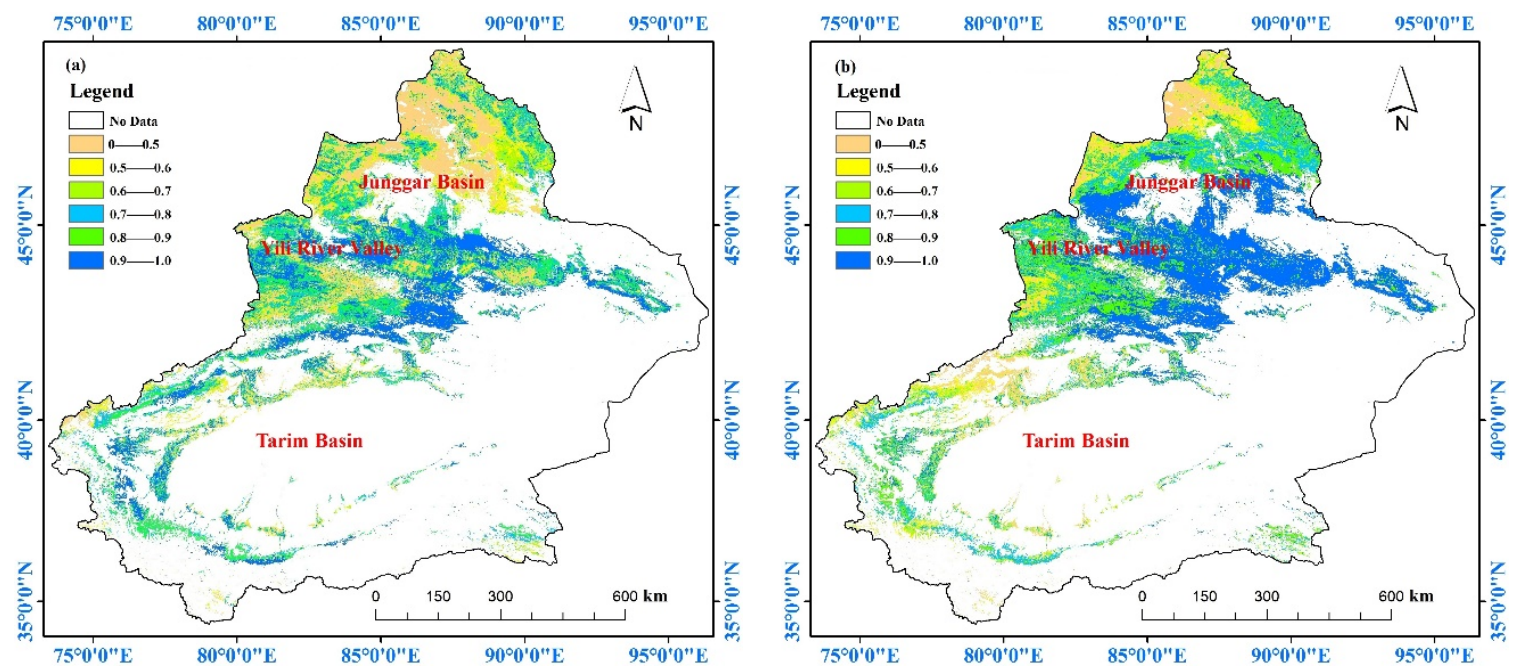

Figure 5. Spatial distribution of Hurst index in Xinjiang from 2000 to 2014.(a) E; (b) Ep.

\subsection{Spatiotemporal Characteristic of WUEs Defined by GPP/E, GPP/Et and GPP/P}

There are obvious spatial differences between different WUEs in which the spatial distribution patterns of eWUE and pWUE are generally consistent. Spatiotemporal WUE (2000-2014 average) consists of GPP/E (eWUE), GPP/Et (tWUE), and GPP/P (pWUE) (Figure 6). During the period of 2000-2014, the value of WUE showed slight changes, and the spatial distribution of WUEs was uneven (the white area means no value). The spatial distribution of eWUE presents a high-low interval distribution. The eWUE around the Taklimakan Desert was relatively high, indicating that the WUE of the desert ecosystem is generally high. However, the tWUE around the Taklimakan Desert is higher than the eWUE. Secondly, the spatial distribution of pWUE and eWUE is basically the same (Figure $6 \mathrm{a}, \mathrm{c})$, but they are different from the trend of tWUE. It shows that precipitation and evapotranspiration have consistent changes in semi-arid areas. In arid areas, $90 \%$ of the surface precipitation returns to the atmosphere in the form of vapor [45,46]; therefore, the precipitation and evaporation show the same pattern. The range of WUE was $0-5 \mathrm{~g} \mathrm{C} \cdot \mathrm{mm}^{-1} \cdot \mathrm{m}^{-2}$, and Zou Jie et al. analyzed the range of nearly 15 ecosystems in Central Asia and Xinjiang, confirming the accuracy of the calculation results [41]. We normalized data from $0-5$, mapped them to values between $0-1$, and divided WUE into five levels for statistical analysis (Table 2): When $0<$ WUE $<0.2$, the proportion of eWUE and pWUE is similar $(65.25 \%$ and $67.11 \%)$, but the proportion of tWUE $(23.66 \%)$ is less than eWUE and pWUE. When $0.2<$ WUE $<0.4$, overall, the values of eWUE and pWUE range mainly from $0-0.4$, which is more than $85 \%$ of the total area. However, the tWUE at $0-0.2,0.2-0.4$, and $>0.8$ levels accounted for $23.66 \%, 26.78 \%$, and $25.66 \%$, respectively. In summary, the mean annual value of tWUE is larger than that of eWUE and pWUE, 
and the spatial difference is obvious. According to previous studies [47,48], there has been an increase in temperature and precipitation since the mid-1980s, with the increase in precipitation in Xinjiang being particularly significant compared with other regions. However, according to the results of this study, WUEs has a negative effect on precipitation. We think the increase in precipitation is bad news for the vegetation that has adapted to the arid environment. It takes a while for the vegetation to adapt. Such a research phenomenon may be the lag effect. Firstly, we found that there was a high degree of spatial similarity between pWUE and NDVI in the growing season [20]. Secondly, pWUE values were also higher in the regions with higher NDVI values in the growing season, except for sparse vegetation around the desert. Such a phenomenon occurs around the desert. We believe that the reason why pWUE is high around the desert is that mainly coniferous vegetation around the desert leads to the reduction of transpiration, which leads to a high WUE. Finally, we believe that there is a difference between NDVI in the growing season and pWUE, which may be caused by the difference in time scale.
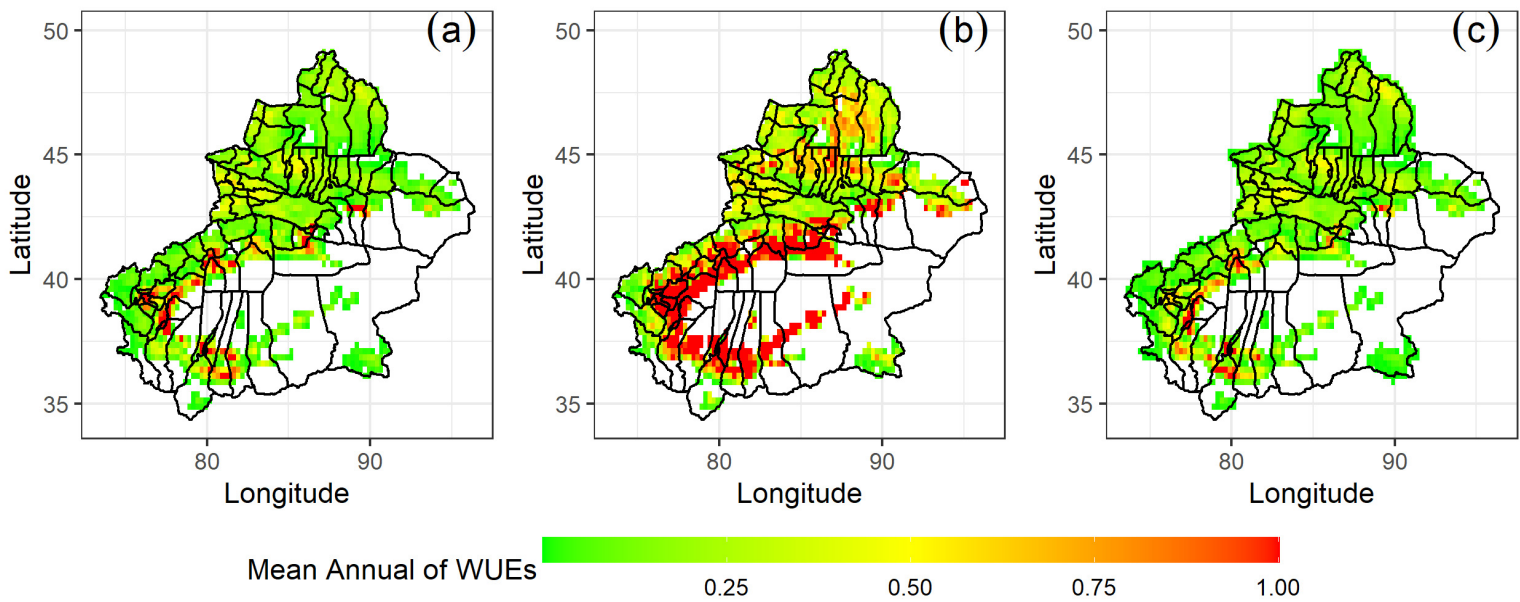

Mean Annual of WUEs

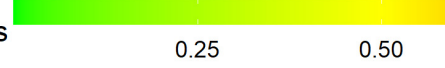

Figure 6. Spatial distribution of WUEs during 2000-2014; (a) eWUE; (b) tWUE; (c) pWUE.

We divided the change trends (Slope) into five categories (Table 1). The regions with increasing eWUE and pWUE accounted for $68.18 \%$ and $81.47 \%$, respectively (Table 2), while the regions with decreasing trends were mainly distributed in the north, central, and a few southern regions of Xinjiang (Figure $7 \mathrm{a}, \mathrm{c})$. Secondly, the area with a slight increasing trend of TWUE accounted for $41.32 \%$. The spatial distribution is scattered and irregular, which is mainly because the vegetation cover distribution and precipitation distribution are jointly determined. Surprisingly, the regions with high and relatively high increasing trends in southern Xinjiang accounted for $5.74 \%$ of the total. This phenomenon is mainly due to the relatively large fluctuations caused by farmland and irrigation in southern Xinjiang (Figure 7b). The tWUE change greatly compared with eWUE and pWUE, which indicates that the tWUE of arid and semi-arid areas changes significantly due to the strong fluctuation of the transpiration of vegetation [49].
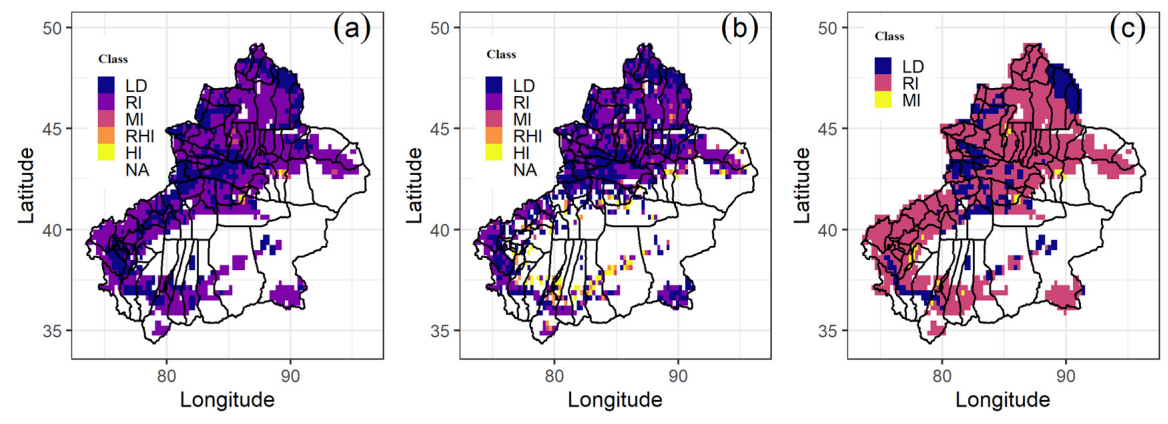

Figure 7. Latitude change trend of WUEs; (a) eWUE; (b) tWUE; (c) pWUE. 
Table 2. Trend change and mean annual of WUEs percentage (units: \%).

\begin{tabular}{ccccccccccc}
\hline & \multicolumn{4}{c}{ Trend of WUEs } & \multicolumn{4}{c}{ Mean Annual of WUEs } \\
\hline Class & LD & RI & MI & RHI & HI & $0-0.2$ & $0.2-0.4$ & $0.4-0.6$ & $0.6-0.8$ & $>0.8$ \\
eWUE & 31.57 & 66.87 & 0.81 & 0.31 & 0.19 & 65.25 & 23.64 & 5.18 & 1.68 & 4.24 \\
tWUE & 34.77 & 41.32 & 3.00 & 2.43 & 3.31 & 23.66 & 26.78 & 15.04 & 8.86 & 25.66 \\
pWUE & 18.54 & 80.13 & 1.34 & 0 & 0 & 67.11 & 22.72 & 5.81 & 1.92 & 2.44 \\
\hline
\end{tabular}

As shown in Figure 7c, pWUE has only three categories, and most regions show a slight increase, accounting for $80.13 \%$. There are no areas of high increase. In conclusion, eWUE and pWUE have basically the same variation pattern, and the tWUE spatial variation trend is not uniform (Figure $7 \mathrm{~b}$ ). Most areas in northern Xinjiang show an upward trend in tWUE, while the changes around the desert are dramatic. This is due to the rising temperature in northern Xinjiang with increasing precipitation, resulting in increased vegetation photosynthesis and a steaming effect [12,50]. However, the drastic diurnal temperature difference in the desert leads to the unstable changes of vegetation photosynthesis and water loss, resulting in drastic changes of tWUE.

The increase in atmospheric $\mathrm{CO}_{2}$ emissions caused global warming, which in theory could result in an increase in WUE. High temperatures inhibit photosynthesis and promote an increase in actual steaming emissions, which ultimately led to a decrease in WUE [51,52].

\subsection{WUEs Responds to Temperature and Precipitation Thresholds}

Numerous studies have shown that climatic condition is an important environmental factor that affects the water use efficiency of terrestrial ecosystems [52,53]. There is a threshold effect of both temperature and precipitation on WUEs. Xue et al. (2015) found that WUE was positively correlated with air temperature when the temperature was below $18.5^{\circ} \mathrm{C}(p<0.05)$, and it significantly decreased when the temperature was between 18.5 and $25.7^{\circ} \mathrm{C}(p<0.05)$ [54]. However, this study indicates that the response of diverse types of water use efficiency to temperature fluctuation is different in semi-arid area. Figure $8 b, d, f$ show that water use efficiency is proportional to temperature. Due to the increased stomatal conductance of vegetation leaves, the increase in photosynthetic rate is greater than that the transpiration rate, resulting in an increase in WUE. The temperature thresholds of WUEs in different hydrological processes are different. Figure $8 b, d, f$ show that the temperature, when around $-10-2{ }^{\circ} \mathrm{C}$, is proportional to eWUE. However, when the temperature is greater than $2{ }^{\circ} \mathrm{C}$, the correlation between temperature and eWUE fluctuates. Temperature is also proportional to tWUE when it is within the range of $-10-7^{\circ} \mathrm{C}$. Similarly, the pWUE and eWUE thresholds are basically the same.

The thresholds of this paper differ from those of Xue et al. [54], which is mainly because different regional climates influence the changes in thresholds. The study by Liu et al. (2015) on Chinese terrestrial ecosystems shows that most of the vegetation WUE has a positive response threshold of $500 \mathrm{~mm}$ to precipitation [55]; however, our study does not find such a pattern, and this may be due to the influence of arid climate characteristics. There is a positive correlation between eWUE and precipitation, which indicates that precipitation has a positive response to eWUE. From Figure $8 \mathrm{a}, \mathrm{c}, \mathrm{e}$, it can be seen that for eWUE, when precipitation is less than $300 \mathrm{~mm}$, precipitation is proportional to eWUE; when precipitation is greater than $300 \mathrm{~mm}$, precipitation is negatively correlated with eWUE. For tWUE, when precipitation is less than 200, precipitation has a positive relationship with tWUE; when precipitation is greater than $200 \mathrm{~mm}$, precipitation and eWUE exhibit a negative correlation. The pWUE and eWUE threshold are basically the same. The standard precipitation threshold in this paper is different from that of Liu et al. [55]. This is mainly because the small average annual precipitation in Xinjiang affects the change of threshold value.

The sensitive coefficient in Figure 9 shows the response of WUEs to climate factors. From Figure $9 \mathrm{a}$,e it can be seen that tWUE has the largest response to temperature $(S p=0.4)$ (Figure 9a); tWUE has the greatest response to precipitation $(S p=1.0)$ (Figure 9e). tWUE 
responds more quickly to precipitation but responds more slowly to temperature. This shows that the effect of temperature on vegetation has a lag effect.

(a)

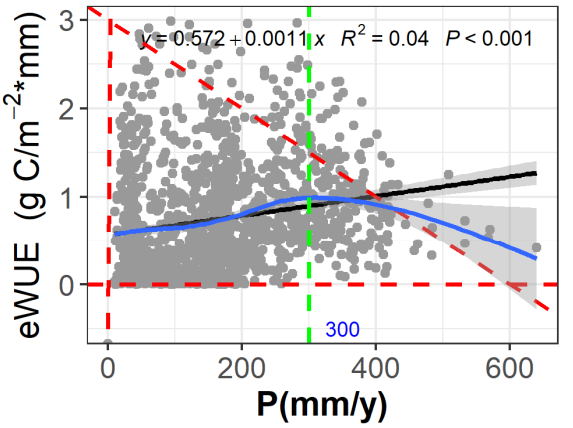

(c)

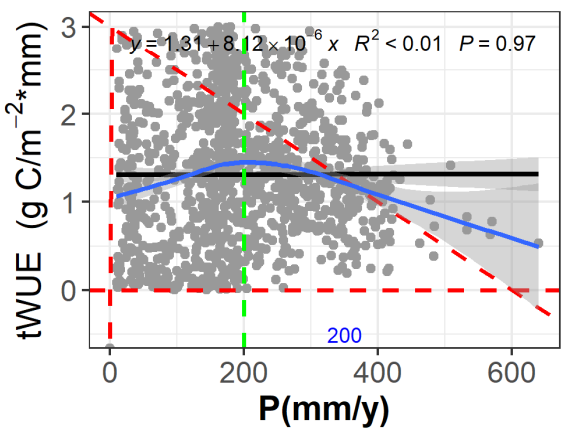

(e)

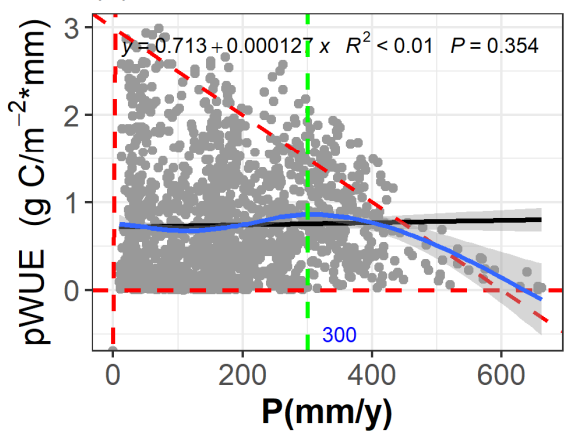

(b)

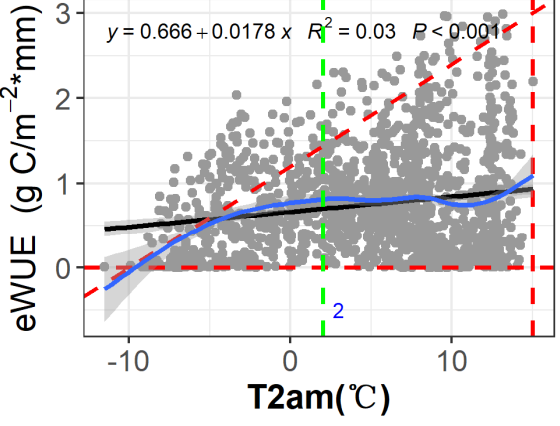

(d)

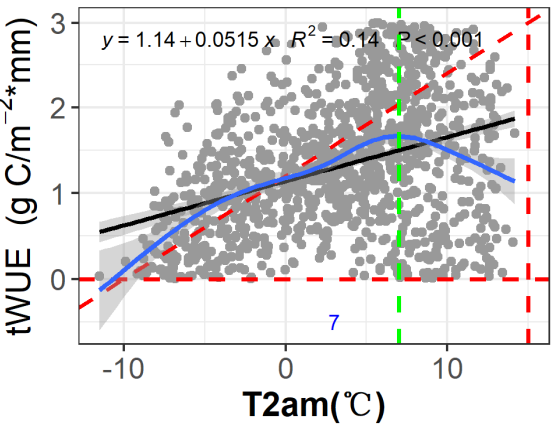

(f)

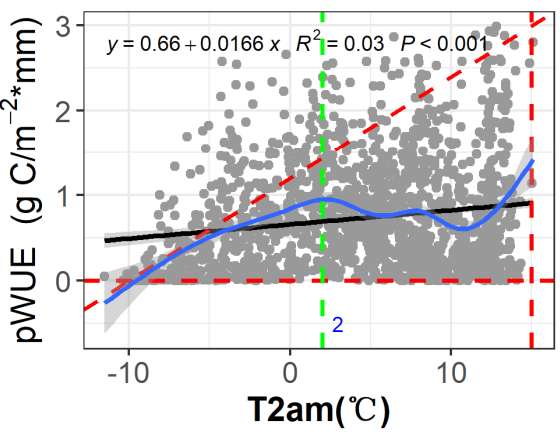

Figure 8. Relationship between precipitation, temperature, and WUEs. (The black line represents linear fitting; the blue line represents the variation trend of the fitting points. The gray is the $95 \%$ confidence interval, and the dashed green line is the threshold.)

The red line in Figure 8 shows the constraint analysis of all metadata in the semi-arid region. It was surprising to find two symmetrical "triangular" relationships between precipitation, temperature, and water use efficiency in the point distribution. From Figure 8a,c,e, we can see that the relationship between precipitation and WUEs shows a "left triangle shape". This indicates that in the semi-arid zone, an increase in precipitation does not in the meantime increase the water use efficiency. Due to the low fluctuation in the response of semi-arid vegetation to water, there is a lagged effect, which is consistent with the findings of Zou et al. (2018) [56], who suggested that there is a lagged effect of drought on ecosystem WUE. However, the relationship between air temperature and WUEs showed a "right triangle" shape, indicating that air temperature contributes to WUEs. This pattern is currently seen to be specific to semi-arid regions. 


\subsection{WUEs Responds to Temperature and Precipitation}

From 2000 to 2014, a significant spatial difference in the sensitivity of WUEs to precipitation and temperature in Xinjiang can be observed (Figure 9), while the negative region of precipitation to WUEs was significantly larger than the positive regions. Precipitation is positively correlated with eWUE and tWUE Figure 9d,e in central Xinjiang, while the vast majority of the rest is negatively correlated. Among them, the negative correlation between precipitation and EWUE accounts for $88.8 \%$ of the region (Figure $9 \mathrm{~d}$ ); the negative correlation between precipitation and tWUE accounted for $84.8 \%$ of the region (Figure 9e); and the negative correlation between precipitation and pWUE prevailed throughout the region (Figure 9f).

It is shown that the sensitivity of vegetation transpiration to precipitation is relatively negative compared with evapotranspiration, and the difference is estimated in part because ecosystem evapotranspiration includes evaporation from exposed soils. The increase in precipitation in arid areas leads to the decrease in WUE, since the increase in ET is greater than the increase in photosynthesis. On the contrary [57], the decrease in precipitation leads to the increase in WUE in the region, because the decrease in ET is greater than the decrease in GPP [58], and the threshold effect on WUE may be related to the effective precipitation in the region.

From the spatial perspective, there is a positive correlation between temperature and WUEs, and the proportion of positive correlation is 70.5\% (eWUE), 68.3\% (tWUE), and $81.3 \%$ (pWUE), respectively (Figure $9 \mathrm{a}, \mathrm{b}, \mathrm{c}$ ). The positive correlation area is mainly distributed in the north of Xinjiang, because the north of Xinjiang is the main agricultural area in Xinjiang, and the response of irrigation and farmland to temperature is more positive [45]. However, the southern region of Xinjiang is more scattered and has both positive and negative relationships, which may be related to the local geographical location and temperature inequality caused by deserts. The negative values are mainly distributed in the central and southern regions of Xinjiang, as the negative values are located near low latitude and have sufficient thermal energy. This region is highly sensitive to precipitation (Figure 9d-f).
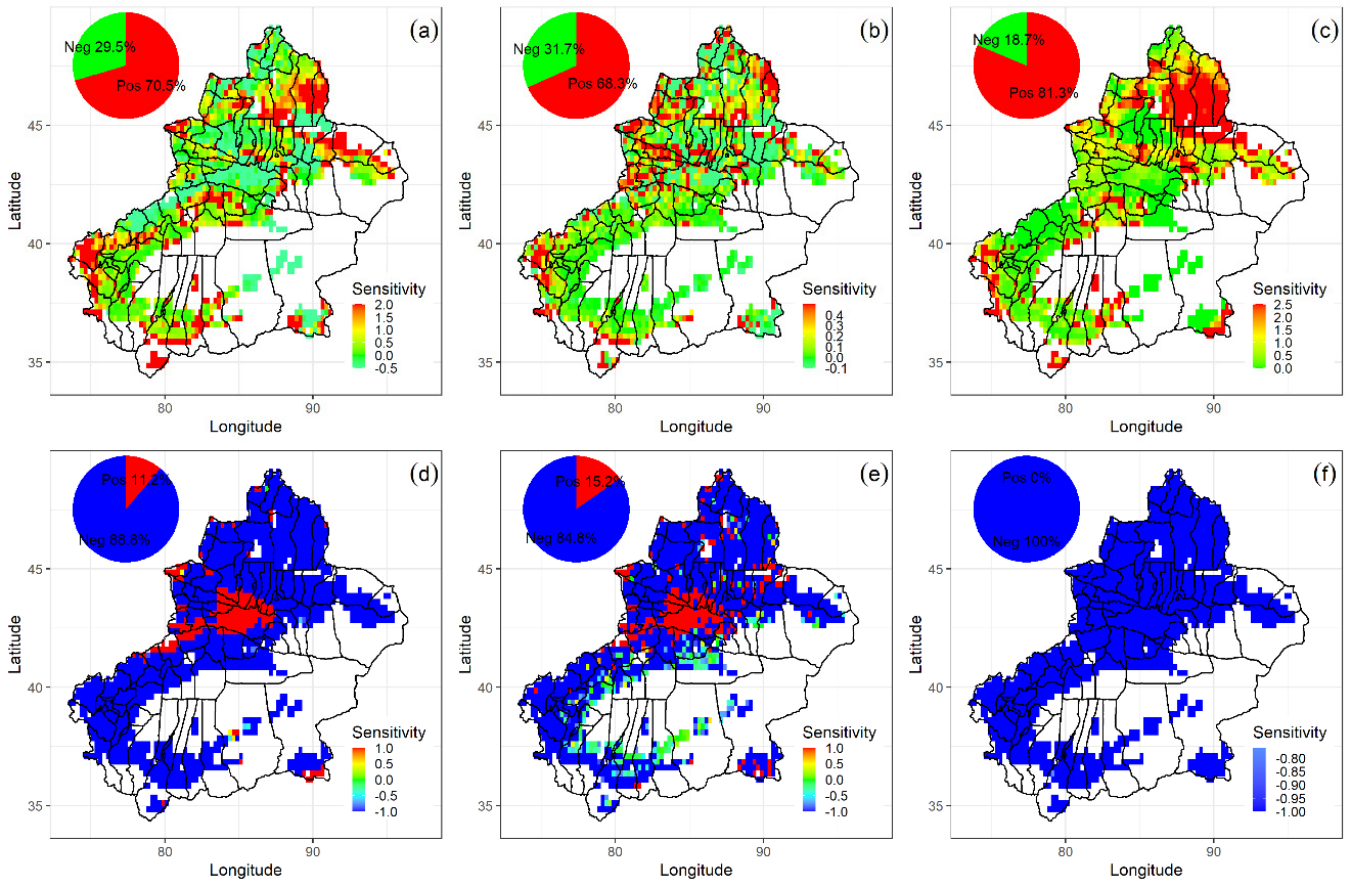

Figure 9. WUEs sensitivity coefficient to precipitation and temperature (a), (b), and (c) respectively represent the sensitivity coefficient of temperature to eWUE, tWUE, and pWUE; (d), (e), and (f) respectively represent the sensitivity coefficient of precipitation to eWUE, tWUE, and pWUE; the upper left illustration shows the proportion of positive (Pos) and negative (Neg) sensitivities. 


\section{Conclusions}

This study of water use efficiency (WUE) of different hydrological processes helps to shed new light on the response of hydrological processes and ecosystems to climate change and provides valuable approaches for further research. In particular, we found that in the past 15 years (2000-2014), the seasonal fluctuation of evapotranspiration in arid areas was large and the interannual variation was unstable, which was mainly due to the continuous "warm and wet" phenomenon in the northwest of China. The spatial variations of WUE in different hydrological processes were significant, and the trend of WUE in most regions showed an upward trend (eWUE (68.43\%); tWUE (65.23\%); pWUE (81.46\%)). We also found that in arid areas, temperature has a positive effect on WUE, while precipitation has a lagging effect on WUE. Secondly, the threshold value of precipitation to WUEs (200 or $300 \mathrm{~mm}$ ) and temperature to WUEs $\left(2\right.$ or $\left.7^{\circ} \mathrm{C}\right)$ are also different from previous studies. The causes of the differences require further studies.

Author Contributions: Data curation, F.Z. and S.-S.Y.; Investigation, F.Z.; Supervision, Y.-Y.T.; Writing-original draft, Y.-Y.T.; Writing—review and editing, J.-P.C. All authors have read and agreed to the published version of the manuscript.

Funding: This research was funded by the by the China-Geological Survey Bureau Coastal Zone and Island Reef Military-civilian Integration Geological Survey Project [Grant No. DD20208017].

Institutional Review Board Statement: Not applicable.

Informed Consent Statement: Not applicable.

Data Availability Statement: The data presented in this study are available on request from the corresponding author.

Conflicts of Interest: The authors declare that they have no known competing financial interests or personal relationships that would influence the work reported in this paper.

\section{Appendix A}
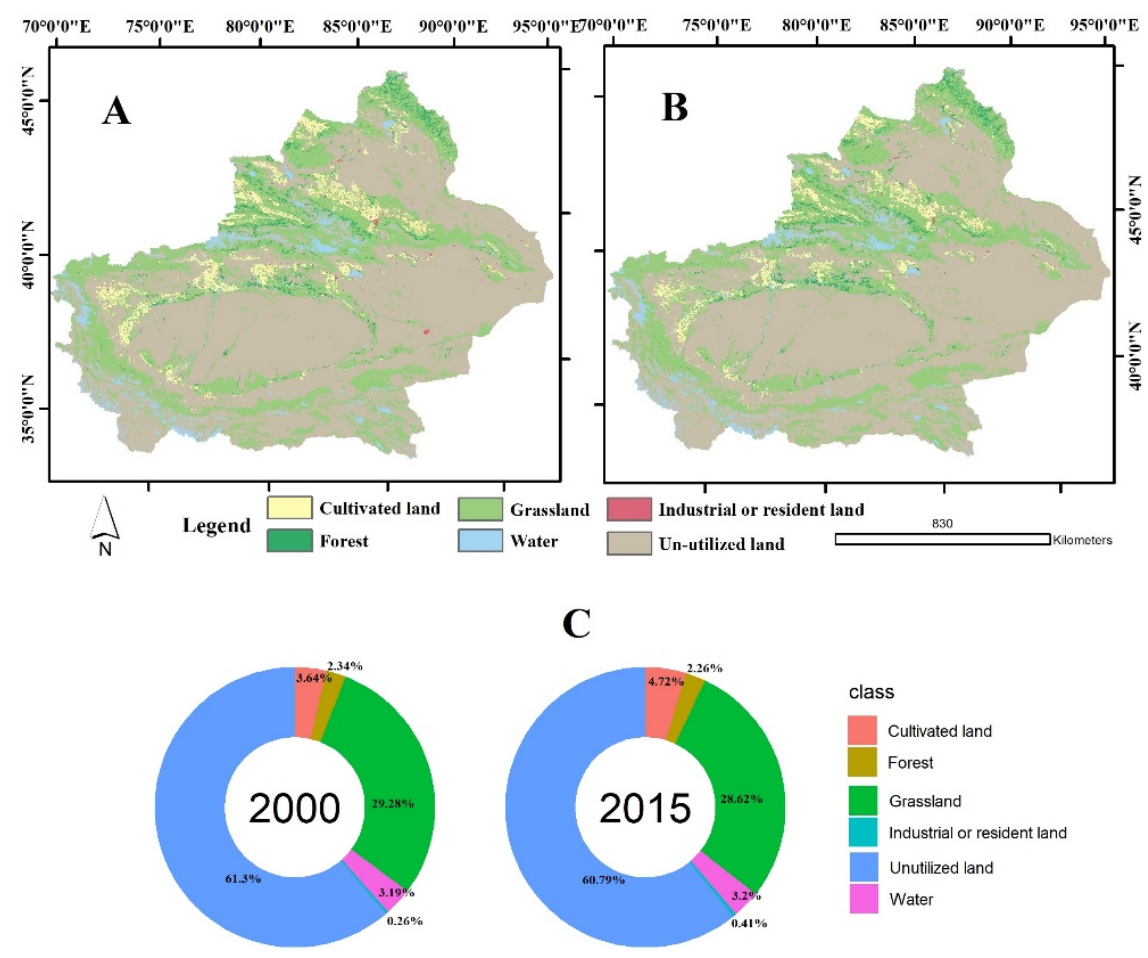

Figure A1. The LULC of Xinjiang in 2000 (A) and 2015 (B,C) Pie chart showing the percentage of land type. 


\section{References}

1. Zhao, M.; Running, S.W. Drought-Induced Reduction in Global Terrestrial Net Primary Production from 2000 Through 2009. Science 2010, 329, 940-943. [CrossRef]

2. Zhang, Z.; Jiang, H.; Liu, J.; Zhou, G.; Liu, S.; Zhang, X. Assessment on water use efficiency under climate change and heterogeneous carbon dioxide in China terrestrial ecosystems. Procedia Environ. Sci. 2012, 13, 2031-2044. [CrossRef]

3. Ponce-Campos, G.E.; Moran, M.S.; Huete, A.; Zhang, Y.G.; Bresloff, C.; Huxman, T.E.; Eamus, D.; Bosch, D.D.; Buda, A.R.; Gunter, S.A.; et al. Ecosystem resilience despite large-scale altered hydro-climatic conditions. Nature 2013, 494, 349-352. [CrossRef] [PubMed]

4. Huang, M.; Piao, S.; Sun, Y.; Ciais, P.; Cheng, L.; Mao, J.; Poulter, B.; Shi, X.; Zeng, Z.; Wang, Y. Change in terrestrial eco-sys-tem water-use efficiency over the last three decades. Glob. Chang. Biol. 2015, 21, 2366-2378. [CrossRef] [PubMed]

5. Reichstein, M.; Ciais, P.; Papale, D.; Valentini, R.; Running, S.; Viovy, N.; Cramer, W.; Granier, A.; Ogée, J.; Allard, V.; et al. Reduction of ecosystem productivity and respiration during the European summer 2003 climate anomaly: A joint flux tower, remote sensing and modelling analysis. Glob. Chang. Biol. 2007, 13, 634-651. [CrossRef]

6. Keenan, T.F.; Hollinger, D.Y.; Bohrer, G.; Dragoni, D.; Munger, J.W.; Schmid, H.P.; Richardson, A.D. Increase in forest water-use efficiency as atmospheric carbon dioxide concentrations rise. Nat. Cell Biol. 2013, 499, 324-327. [CrossRef]

7. Liu, X.; Hu, B.; Ren, Z. Spatiotemporal variation of water use efficiency and its driving forces on the Loess Plateau during 2000-2014. Sci. Agric. Sin. 2018, 51, 302-314.

8. Zhou, S.; Yu, B.; Schwalm, C.R.; Ciais, P.; Zhang, Y.; Fisher, J.B.; Wang, G. Response of water use efficiency to global environmental change based on output from terrestrial biosphere models. Glob. Biogeochem. Cycles 2017, 31, 1639-1655. [CrossRef]

9. Woodward, C.; Shulmeister, J.; Larsen, J.; Jacobsen, G.E.; Zawadzki, A. The hydrological legacy of deforestation on global wetlands. Science 2014, 346, 844-847. [CrossRef]

10. Zheng, H.; Lin, H.; Zhou, W.; Bao, H.; Zhu, X.; Jin, Z.; Song, Y.; Wang, Y.; Liu, W.; Tang, Y. Revegetation has increased ecosystem water-use efficiency during 2000-2014 in the Chinese Loess Plateau: Evidence from satellite data. Ecol. Indic. 2019, 102, 507-518. [CrossRef]

11. Tian, H.; Chen, G.; Liu, M.; Zhang, C.; Sun, G.; Lu, C.; Chappelka, A. Model estimates of net primary productivity, evapotranspiration, and water use efficiency in the terrestrial ecosystems of the southern United States during 1895-2007. For. Ecol. Manag. 2010, 259, 1311-1327. [CrossRef]

12. Huang, M.; Piao, S.; Zeng, Z.; Peng, S.; Ciais, P.; Cheng, L.; Wang, Y. Seasonal responses of terrestrial ecosystem wateruse efficiency to climate change. Glob. Chang. Biol. 2016, 22, 2165-2177. [CrossRef]

13. Yang, Y.; Guan, H.; Batelaan, O.; McVicar, T.; Long, D.; Piao, S.; Liang, W.; Liu, B.; Jin, Z.; Simmons, C.T. Contrasting responses of water use efficiency to drought across global terrestrial ecosystems. Sci. Rep. 2016, 6, 23284. [CrossRef]

14. Sun, Y.; Piao, S.; Huang, M.; Ciais, P.; Zeng, Z.; Cheng, L.; Zeng, H. Global patterns and climate drivers of water-use efficiency in terrestrial ecosystems deduced from satellite-based datasets and carbon cycle models. Glob. Ecol. Biogeogr. 2016, 25, 311-323. [CrossRef]

15. Li, S.C.; Cai, Y.L. Some scaling issues of geography. Geogr. Res. 2005, 24, 11-18.

16. Li, X.J.; Zhang, F.P.; Wang, H.W.; Veroustraete, F. Analysis of Spatio-Temporal Characteristics of water use efficiency of Vegetation and its Relationship with Climate in the Heihe River Basin. J. Desert Res. 2017, 37, 733-741.

17. Hu, Z.; Yu, G.; Fu, Y.; Sun, X.; Li, Y.; Shi, P.; Wang, Y.; Zheng, Z. Effects of vegetation control on ecosystem water use efficiency within and among four grassland ecosystems in China. Glob. Chang. Biol. 2008, 14, 1609-1619. [CrossRef]

18. Yao, J.; Zhao, Y.; Chen, Y.; Yu, X.; Zhang, R. Multi-scale assessments of droughts: A case study in Xinjiang, China. Sci. Total Environ. 2018, 630, 444-452. [CrossRef]

19. Xu, C.; Chen, Y.; Yang, Y.; Hao, X.; Shen, Y. Hydrology and water resources variation and its response to regional climate change in Xinjiang. J. Geogr. Sci. 2010, 20, 599-612. [CrossRef]

20. Yu, H.; Bian, Z.; Mu, S.; Yuan, J.; Chen, F. Effects of Climate Change on Land Cover Change and Vegetation Dynamics in Xinjiang, China. Int. J. Environ. Res. Public Health 2020, 17, 4865. [CrossRef]

21. White, M.A.; Brunsell, N.; Schwartz, M.D. Vegetation phenology in global change studies. Phenol. Integr. Environ. Ment. Sci. 2003, 39, 453-466.

22. Chen, Y.; Li, Z.; Fang, G.; Li, W. Large Hydrological Processes Changes in the Transboundary Rivers of Central Asia. J. Geophys. Res. Atmos. 2018, 123, 5059-5069. [CrossRef]

23. Shen, T.; Su, H.C.; Wang, G.Y.; Mao, W.M.; Wang, S.D.; Han, P.; Wang, N.; Li, Z.Q. The Responses of Glaciers and Snow Cover to Climate Change in Xinjiang (I): Hydrological Effects. J. Glaciol. Geocryol. 2013, 35, 513-527.

24. Xu, C.; Li, J.; Zhao, J.; Gao, S.; Chen, Y. Climate variations in northern Xinjiang of China over the past 50 years under global warming. Quat. Int. 2015, 358, 83-92. [CrossRef]

25. Miralles, D.G.; Holmes, T.R.H.; De Jeu, R.A.M.; Gash, J.H.; Meesters, A.G.C.A.; Dolman, A.J. Global land-surface evaporation estimated from satellite-based observations. Hydrol. Earth Syst. Sci. 2011, 15, 453-469. [CrossRef]

26. Vicente-Serrano, S.; Miralles, D.; Domínguez-Castro, F.; Azorin-Molina, C.; ElKenawy, A.; McVicar, T.; Tomas-Burguera, M.; Beguería, S.; Maneta, M.; Peña-Gallardo, M. Global assessment of the standardized Evapotranspiration Deficit Index (SEDI) for drought analysis and monitoring. J. Clim. 2018, 31, 5371-5393. [CrossRef] 
27. Long, B.; Zhang, B.; He, C.; Shao, R.; Tian, W. Is There a Change From a Warm-Dry to a Warm-Wet Climate in the Inland River Area of China? Interpretation and Analysis Through Surface Water Balance. J. Geophys. Res. Atmos. 2018, 123, 7114-7131. [CrossRef]

28. Li, S.; Wang, G.; Sun, S.; Chen, H.; Bai, P.; Zhou, S.; Huang, Y.; Wang, J.; Deng, P. Assessment of Multi-Source Evapotranspiration Products over China Using Eddy Covariance Observations. Remote. Sens. 2018, 10, 1692. [CrossRef]

29. Allen, R.G.; Pereira, L.; Raes, D.; Smith, M. Crop evapotranspiration: Guidelines for computing crop water requirements. In $F A O$ Irrigation and Drainage Paper 56; FAO: Rome, Italy, 1998.

30. Junde, W. Variations of Land Evapotranspiration in the Plain of the Middle Reaches of Heihe River in the Recent 35 Years. J. Glaciol. Geocryol. 2007, 29, 406-412.

31. Peng, S.; Ding, Y.; Liu, W.; Li, Z. 1 km monthly temperature and precipitation dataset for China from 1901 to 2017. Earth Syst. Sci. Data 2019, 11, 1931-1946. [CrossRef]

32. Peng, S.; Gang, C.; Cao, Y.; Chen, Y. Assessment of climate change trends over the Loess Plateau in China from 1901 to 2100. Int. J. Clim. 2018, 38, 2250-2264. [CrossRef]

33. Ding, Y.; Peng, S. Spatiotemporal Trends and Attribution of Drought across China from 1901-2100. Sustainability 2020, 12, 477. [CrossRef]

34. Zhao, M.; Running, S.W.; Nemani, R.R. Sensitivity of moderate resolution imaging spectroradiometer (modis) terrestri-al primary production to the accuracy of meteorological reanalyses. J. Geophys. Res. Biogeoences 2015, 111, 1-13. [CrossRef]

35. White, M.A.; Thornton, P.E.; Running, S.W.; Nemani, R.R. Parameterization and sensitivity analysis of the BIOME-BGC terrestrial ecosystem model: Net primary production controls. Earth Interact. 2000, 4, 1-84. [CrossRef]

36. Heinsch, F.; Zhao, M.; Running, S.; Kimball, J.; Nemani, R.; Davis, K.; Bolstad, P.; Cook, B.; Desai, A.; Ricciuto, D.; et al. Evaluation of remote sensing based terrestrial productivity from MODIS using regional tower eddy flux network observations. IEEE Trans. Geosci. Remote. Sens. 2006, 44, 1908-1925. [CrossRef]

37. Milich, L.; Weiss, E. GAC NDVI inter-annual coefficient of variation (CoV) images: Ground truth sampling of the Sahel along north-south transects. Int. J. Remote. Sens. 2000, 21, 235-260. [CrossRef]

38. Guli.jiapaer, G.; Liang, S.; Yi, Q.; Liu, J. Vegetation dynamics and responses to recent climate change in Xinjiang using leaf area index as an indicator. Ecol. Indic. 2015, 58, 64-76. [CrossRef]

39. Yang, S.; Zhang, J.; Zhang, S.; Wang, J.; Bai, Y.; Yao, F.; Guo, H. The potential of remote sensing-based models on global wateruse efficiency estimation: An evaluation and inter comparison of an ecosystem model (BESS) and algorithm (MODIS) using site level and upscaled eddy covariance data. Agric. For. Meteorol. 2020, 287, 107959. [CrossRef]

40. Wang, D.; Zhang, F.; Yang, S.; Xia, N.; Ariken, M. Exploring the spatial-temporal characteristics of the aerosol optical depth (AOD) in Central Asia based on the moderate resolution imaging spectroradiometer (MODIS). Environ. Monit. Assess. 2020, 192, 1-15. [CrossRef] [PubMed]

41. Zou, J.; Ding, J.; Welp, M.; Huang, S.; Liu, B. Using MODIS data to analyse the ecosystem water use efficiency spa-tial-temporal variations across Central Asia from 2000 to 2014. Environ. Res. 2020, 182, 108985. [CrossRef] [PubMed]

42. Gu, C.; Tang, Q.; Zhu, G.; Ma, J.; Gu, C.; Zhang, K.; Niu, S. Discrepant responses between evapotranspiration-and tran-spiration based ecosystem water use efficiency to inter annual precipitation fluctuations. Agric. For. Meteorol. 2021, 303, 108385. [CrossRef]

43. Kim, H.W.; Hwang, K.; Mu, Q.; Lee, S.O.; Choi, M. Validation of MODIS 16 global terrestrial evapotranspiration products in various climates and land cover types in Asia. Ksce J. Civ. Eng. 2012, 16, 229-238. [CrossRef]

44. Yin, Y.; Wu, S.; Zheng, D.; Yang, Q. Regional difference of aridity/ humidity conditions change over China during the last thirty years. Chin. Sci. Bull. 2005, 50, 2226-2233. [CrossRef]

45. Zhang, H.; Song, J.; Wang, G.; Wu, X.; Li, J. Spatiotemporal characteristic and forecast of drought in northern Xinjiang, China. Ecol. Indic. 2021, 127, 107712. [CrossRef]

46. He, Y.B.; Su, Z.; Li, J.; Wang, S.L. Regional evapotranspiration of different land covers based on remotesensing. Chin. J. Appl. Ecol. 2007, 18, 288-296.

47. Wang, Q.; Zhai, P.; Qin, D. New perspectives on «warming-wetting» trend in Xinjiang, China. Adv. Clim. Chang. Res. 2020, 11, 252-260. [CrossRef]

48. Song, L.L.; Yin, Y.H.; Wu, S.H. Advancements of the metrics of evapotranspiration. Prog. Geogr. 2012, 31, 1186-1195.

49. Kaufmann, R.K.; Kauppi, H.; Mann, M.L.; Stock, J.H. Reconciling anthropogenic climate change with observed temper-ature 1998-2008. Sch. Artic. 2011, 108, 11790-11793.

50. Gong, T.; Lei, H.; Yang, D.; Liu, T.; Duan, L. Assessing impacts of extreme water and temperature conditions on carbon fluxes in two desert shrub lands. J. Hydroelectr. Eng. 2018, 37, 32-46.

51. DeLucia, E.H.; Drake, J.; Thomas, R.B.; Gonzalez-Meler, M. Forest carbon use efficiency: Is respiration a constant fraction of gross primary production? Glob. Chang. Biol. 2007, 13, 1157-1167. [CrossRef]

52. Xia, L.; Wang, F.; Mu, X.; Jin, K.; Sun, W.; Gao, P.; Zhao, G. Water use efficiency of net primary production in global terres-trial ecosystems. J. Earth Syst. Sci. 2015, 124, 921-931. [CrossRef]

53. Zhang, F.; Ju, W.; Shen, S.; Wang, S.; Yu, G.; Han, S. How recent climate change influences water use efficiency in East Asia. Theor. Appl. Clim. 2013, 116, 359-370. [CrossRef]

54. Xue, B.-L.; Guo, Q.; Otto, A.; Xiao, J.; Tao, S.; Li, L. Global patterns, trends, and drivers of water use efficiency from 2000 to 2013. Ecosphere 2015, 6, art174. [CrossRef] 
55. Liu, Y.; Xiao, J.; Ju, W.; Zhou, Y.; Wang, S.; Wu, X. Water use efficiency of China's terrestrial ecosystems and responses to drought. Sci. Rep. 2015, 5, 13799. [CrossRef] [PubMed]

56. Zou, J.; Ding, J.L.; Qin, Y.; Wang, F. Response of water use efficiency of Central Asia ecosystem to drought based on remote sensing data. Trans. CSAE. 2018, 34, 145-152. (In Chinese)

57. Zhang, Y.; Yu, G.; Yang, J.; Wimberly, M.; Zhang, X.; Tao, J.; Jiang, Y.; Zhu, J. Climate-driven global changes in carbon use efficiency. Glob. Ecol. Biogeogr. 2013, 23, 144-155. [CrossRef]

58. Salve, R.; Sudderth, E.A.; Clair, S.B.S.; Torn, M.S. Effect of grassland vegetation type on the responses of hydrological processes to seasonal precipitation patterns. J. Hydrol. 2011, 410, 51-61. [CrossRef] 